\title{
Nutrition and fetal growth: paradoxical effects in the overnourished adolescent sheep
}

\author{
J. M. Wallace, D. A. Bourke and R. P. Aitken \\ The Rowett Research Institute, Greenburn Road, Bucksbum, Aberdeen, UK
}

\begin{abstract}
Inappropriate maternal nutrient intake at key developmental timepoints during ovine pregnancy has a profound influence on the outcome of pregnancy and aspects of postnatal productivity. However, the responses to alterations in maternal nutrition in adult sheep are often highly variable and inconsistent between studies. The growing adolescent sheep provides a new, robust and nutritionally sensitive paradigm with which to study the causes, consequences and reversibility of prenatal growth restriction. Overnourishing the adolescent dam to promote rapid maternal growth throughout pregnancy results in a major restriction in placental mass, and leads to a significant decrease in birthweight relative to moderately fed, normally growing adolescents of equivalent gynaecological age. Maternal insulin and IGF-I concentrations are increased from an early stage of gestation in overnourished adolescent dams and these hormones ensure that the anabolic drive required to promote maternal tissue synthesis is initiated at a time when the nutrient requirements of the gravid uterus are low. The major restriction in fetal growth in rapidly growing dams occurs irrespective of high concentrations of essential nutrients in the maternal circulation and suggests that the small size or altered metabolic and transport capacity of the placenta is the primary constraint to fetal growth. The decrease in placental weight in the overnourished animals reflects a significant reduction in both fetal cotyledon number and mean cotyledon weight. The role of nutritionally mediated alterations in progesterone and the components of the IGF system in this early pregnancy placental phenomenon are being investigated. Nutritional switch-over studies have demonstrated that reducing maternal nutrient intake at the end of the first third of pregnancy can stimulate placental growth and enhance pregnancy outcome, but increasing nutrient intake at this time has a deleterious effect on placental development and fetal growth.
\end{abstract}

\section{Introduction}

Alterations in the prenatal growth process influence both size and viability at birth. Low birthweight lambs have a relatively large surface area per unit weight, reduced insulation and inadequate lipid reserves, and depending on climatic conditions perinatally, have an increased risk of either hypothermia or dehydration and heat stress (Alexander, 1974). Low birthweight lambs are unable to compete with larger siblings for colostrum and hence are vulnerable to both starvation and infection during neonatal life. For those animals that survive the rigours of the early neonatal period, the long-term consequences of prenatal growth restriction include reduced postnatal and skeletal growth, altered carcass composition and failure to attain mature body size (reviewed by Bell, 1992). In addition, there is evidence that undernutrition during fetal life reduces lifetime reproductive capability (Williams, 1984; Gunn et al., 1995) and the quality and quantity of wool production (Kelly et $a l ., 1996)$. At the other end of the scale, lamb or calf birthweights above the breed norm are associated with an increased incidence of distocia-related neonatal mortality, which has significant welfare and economic implications (Walker et al., 1992).

As $80 \%$ of fetal growth occurs during the final third of pregnancy, it is not surprising that most 
early studies on the effects of nutrition on fetal growth and development concentrated on this period. However, there is an increasing body of evidence that the prenatal growth trajectory is sensitive to maternal dietary intake throughout pregnancy including the earliest stages of embryonic life. This is not unexpected if one considers pregnancy as a continuum from ovulation, fertilization, embryo differentiation, implantation, placental and fetal growth and that pregnancy outcome is dependent on each of the preceding events. As extremes in food intake are a common feature of sheep production systems, this review will concentrate on how alterations in maternal nutrition, at various developmental times during the 145 day gestation period, influence ovine prenatal growth. It will also detail recent studies using a novel adolescent sheep paradigm that has proved to be highly sensitive to maternal dietary intake and which is being used to determine the nutritionally mediated mechanisms underlying prenatal growth restriction and the consequences for the developing fetus.

\section{Periovulatory and Early Pregnancy Nutrition}

Exposure of the early cleavage stage ruminant embryo to a short period of in vitro culture (1-7 days) is associated with fetal oversize and is linked with a longer duration of gestation and high neonatal mortality (Walker et al., 1992; Farin et al., 1994). Culture of sheep embryos for 5 days in synthetic oviduct fluid medium (SOF) containing a human serum supplement before transfer to recipients resulted in lamb birthweights that were significantly higher than those in control spontaneously ovulating dams $(4.2 \pm 0.2$ versus $3.4 \pm 0.2 \mathrm{~kg}, P<0.01$, Thompson et al., 1994). A recent, more stringently controlled study, in which in vivo derived sheep embryos were compared with those cultured in a granulosal cell co-culture system for 5 days, demonstrated that a major enhancement of fetal growth was evident as early as day 61 of pregnancy ( 74.2 versus 84.5 g respectively, $P<0.01$ ) and was independent of placental mass (Sinclair et al., 1997). The increase in weight observed in the fetuses that were derived from co-culture was associated with increased or precocious primary muscle fibre hypertrophy and secondary fibre hyperplasia (Maxfield et al., 1997). The mechanisms whereby different in vitro culture systems influence the growth trajectory of the ruminant embryo are unknown, but could be largely nutritional in origin. Ammonium generated from amino acids in culture inhibits development and cleavage of the sheep blastocyst (Gardner et al, 1994). In vivo, high dietary intakes of rumen degradable nitrogen increase plasma urea and ammonia concentrations, and are associated with increased embryo mortality (McEvoy et al, 1997). However, in the latter study, exposure to ammonium appeared to upregulate protein metabolism in some embryos, and fetal growth was enhanced among those that survived autotransfer. It is conceivable that embryos in culture are being subjected to an inappropriate, nutrient-depleted environment, leading to changes in gene expression, which may be either lethal for the developing embryo or result in an alteration in the growth trajectory. Indirect evidence to support this hypothesis comes from studies using F9 embryonal carcinoma cells that display a differentiation pattern analogous to that of the developing embryo. In this rapidly dividing cell line, amino acid deficiency altered expression of a variety of growth-arrest genes (Fleming et al., 1998). However, it is unknown whether the enhanced in utero growth of in vitro derived embryos reflects a permanent resetting of the growth trajectory, or whether these embryos could be influenced by manipulation of recipient dam nutrition during later stages of prenatal life.

In animals expressing their natural ovulation rate, maternal dietary intake premating and body composition at mating have both been shown to influence embryo survival (reviewed by Rhind, 1992). Short-term increases in maternal dietary intake premating may also influence early embryo development in superovulated animals. High dietary intakes that suppressed progesterone concentrations during the period of follicular recruitment, oocyte maturation and ovulation resulted in embryos that were developmentally retarded both on recovery 4 days after insemination and after $72 \mathrm{~h}$ in culture (McEvoy et al., 1995). It remains to be established whether these embryos would have survived and developed appropriately if returned to a synchronous recipient uterus. Although there are reports that clearly demonstrate that a low plane of nutrition during early pregnancy is 
detrimental to embryo survival (Edey, 1966), the weight of evidence suggests that overfeeding during the early postmating period compromises establishment of pregnancy. In sheep, high intakes equivalent to twice maintenance rations for only 12 or 14 days commencing on day 2 after mating significantly reduced pregnancy rate (Parr et al., 1987) and embryo survival (Cumming et al., 1975). Maternal feed intakes and peripheral progesterone concentrations after mating are inversely related (Williams and Cumming, 1982) and the $20 \%$ reduction in pregnancy rate measured in high intake ewes by Parr et al. (1987) was reversed and enhanced relative to controls by progesterone supplementation on days 8-14 after mating. Administration of epostane, an inhibitor of $3 \beta$ hydroxysteroid dehydrogenase, to reduce the concentration of progesterone for windows of $48 \mathrm{~h}$ between days 9 and 13 after mating revealed that pregnancy rates were lower when progesterone concentrations were temporarily reduced during days 11 and 12 (Parr, 1992). The inhibition of luteolysis and the maintenance of adequate progesterone secretion by the corpus luteum is central to the maternal recognition of pregnancy, and progesterone plays a major role in controlling maternal secretion of nutrients, immunosuppressive agents and enzymes required for successful embryo development at this time. It has been suggested that the mechanisms underlying nutritionally induced differences in pregnancy rate and embryo survival may operate via progesteronedependent modifiçations of protein synthesis by either conceptus or endometrium (Robinson, 1990). Direct evidence to support this hypothesis is lacking. In a highly controlled study at the Rowett Research Institute, we collected embryos from ewes fed maintenance rations and transferred them in singleton on day 3 of the ovarian cycle to ewes receiving a high $(2 \times$ maintenance) or low $(0.7 \times$ maintenance) plane of nutrition from day 0 . Progesterone concentrations were significantly reduced throughout the luteal phase in high intake ewes, but survival and growth of the conceptus at day 16 of pregnancy were equivalent between groups. Furthermore, the ability of the uterine endometrium and conceptus tissues to synthesis and secrete de novo proteins in vitro, and the conceptus secretion of antiluteolytic interferon tau were independent of maternal intake (Wallace et al., 1994).

Studies examining the influence of nutrition during early pregnancy on the prenatal growth trajectory beyond the preimplantation stage generally indicate that food restriction is detrimental to fetal growth. Singleton fetuses of ewes fed a $0.5 \times$ maintenance ration from mating until day 35 of gestation, and therafter fed normally, weighed less at day 35 of gestation. This difference was still evident at day 90 of gestation but did not persist until birth (Parr et al., 1986). A more severe feed restriction ( $0.15 \times$ maintenance) from mating until day 60 of gestation reduced both lamb birthweight and viability by 15 and $36 \%$, respectively (Vincent et al., 1985).

\section{Mid-pregnancy Nutrition}

Previous reviews have highlighted the central role of placental size in the determination of lamb birthweight (Mellor, 1983; Bell, 1984). Maximum proliferative growth of the ovine placenta occurs between days 50 and 60 of gestation (Ehrhardt and Bell, 1995) and placental weight peaks prior to the end of the second trimester of gestation; thus, mid-pregnancy is potentially a critical time when alterations in maternal nutrition may influence placental growth and hence pregnancy outcome. Kelly (1992) reviewed 16 sets of studies that examined the role of mid-pregnancy nutrition on placental growth and found that only two of these failed to demonstrate a significant effect of nutrient intake on placental size. At that time the consensus was that a high plane of nutrition from approximately day 40 to 100 of gestation significantly increased placental weight (nine studies). However, in three studies, ewes on a low plane of nutrition during mid-pregnancy had significantly heavier placentas. This observation has recently been reinforced by Heasman et al. (1998) who suggested that it is the fetal component of the placenta that is enhanced following such dietary restriction. There is evidence of an interaction between maternal liveweight together with body condition score (an indicator of body fat status) at mating and mid-pregnancy nutrition on the growth of the placenta or fetus. Russel et al. (1981) varied feeding levels between days 30 and 98 of gestation in primiparous ewes that were heavy or light at mating and in good or poor body condition, respectively. In ewes that were heavy at mating, feed restriction during mid-pregnancy 
increased lamb birthweight by $17 \%$, while in ewes that were light at mating a low nutrient intake was associated with a $13 \%$ decrease in birthweight. Similar effects have been documented by De Barro et al. (1992) and appear to be mediated by alterations in placental growth and morphology.

\section{Nutrition in Late Pregnancy}

Fetal growth in late pregnancy is clearly dependent on the placental component, particularly if growth of the placenta has been compromised during early or mid-pregnancy. However, where placental growth is normal, it is largely assumed that the availability of essential nutrients in the maternal circulation can directly influence umbilical nutrient uptake and hence fetal growth (Bell, 1984).

Early studies reviewed by Hammond (1944) revealed that in singleton-bearing ewes fed a restricted diet (liveweight gain $0.5 \mathrm{~kg}$ during the last 60 days of pregnancy) versus well nourished animals (gaining $17.7 \mathrm{~kg}$ during the same period), lamb birthweights were similar. In contrast, in twin-bearing animals experiencing the same nutritional treatments, combined lamb birthweight from ewes on the restricted diet was reduced by $33 \%$. It is now generally accepted that failure to increase nutrient intake in the final third of gestation in line with the increasing needs of the rapidly growing fetal load results in a reduction in birthweight. Robinson (1983) reviewed these studies and highlighted the wide variations in the amount of metabolizable energy (ME) required to elicit a given reduction in birthweight, and suggested that this may be due to differences in genotype, maternal reserves and the ME content of the different diets used. These factors, in addition to variable numbers of fetuses carried, differences in climate, housing and exercise, potentially confound interpretation of the effects of maternal nutrition on placental and fetal growth at all the developmental times discussed in this review.

It has been suggested that birthweight is a poor estimation of fetal growth rate, in that a variety of different growth patterns may result in the same final size (Harding and Johnston, 1995). The classic studies of David Mellor, which predate the use of ultrasonography, used a crown-rump length or girth measuring device to measure fetal growth on a daily basis throughout late gestation and provide a valuable insight into the sensitivity of the fetus to both short-and long-term alterations in maternal nutrition. When ewes that had been well fed were severely underfed during the last third of gestation, fetal growth rate decreased markedly within 3 days and resulted in a 20-30\% decrease in birthweight at term (Mellor and Matheson, 1979). When fetuses were exposed to short periods of severe feed restriction of between 7 and 16 days, fetal growth rate generally increased when feed levels were restored. However, no recovery in growth rate occurred if the period of feed restriction was extended to 21 days (Mellor and Murray, 1982). Comparison of severe feed restriction in late pregnancy versus moderate restriction throughout mid-and late pregnancy produced similar reductions in late pregnancy growth rates and fetal weights. The former presumably occurs via a direct effect of nutrient availability in the maternal circulation and the latter via compromised placental growth (Mellor, 1983). More recent data suggest that the response of the fetus to a 10 day period of undernutrition during late pregnancy (days 105-115) may depend on its prior growth rate. Thus, the growth rate of fetuses from ewes that were well nourished for 2 months before until 1 month after mating was more perturbed during a late pregnancy nutritional insult than that of fetuses from ewes that were moderately undernourished during the same periconceptual period and were already growing at a slower rate (Harding and Johnston, 1995).

In late gestation, the adverse effect of feed restriction on birthweight is most pronounced when accompanied by low protein intakes (Robinson, 1983). In this review of data, it was calculated that for ewes receiving ME intakes in late pregnancy that only meet the maintenance requirement of the maternal body, the inclusion of an undegraded protein supplement during the final 3 weeks of pregnancy would increase the birthweight of twin lambs by up to $25 \%$. In field conditions, the effects of supplementary protein in late pregnancy on lamb birthweight have been equivocal, but a recent study has reported a beneficial effect on lamb survival to weaning (Hinch et al., 1996). This is probably due to a stimulatory effect of protein supplementation on colostrum production, as demonstrated by Robinson (1987). 


\section{Nutrition and the Pregnant Adolescent}

In the literature reviewed in the preceding sections, it has clearly been demonstrated that inappropriate maternal nutrition at various developmental times during pregnancy can have a profound influence on pregnancy outcome and postnatal performance in an agriculturally important species. However, the responses to alterations in maternal nutrition have not always been consistent, even when studies have been performed by the same group of researchers using a single genotype. Thus, there is a clear requirement for the development of more rigorously controlled models to investigate the nutritionally mediated causes and consequences of alterations in the prenatal growth process. Human adolescent mothers have a risk of delivering low birthweight and premature infants who exhibit high mortality rates within the first year of life (McAnarney, 1987). The risk of adverse pregnancy outcome is poorly understood but has been attributed to the growth or nutritional status of the mother at the time of conception, or her young gynaecological age (Fraser et al., 1995). At the Rowett Research Institute, we initially developed the sheep model outlined below to resolve this issue and to investigate nutrient partitioning between the maternal and fetal compartments during adolescent pregnancy (Wallace et al., 1996, 1997a). However, it soon became evident that this experimental paradigm has both clinical and agricultural relevance that extends beyond the particular problems of the growing adolescent.

\section{Experimental Model}

Embryo recovery and transfer procedures are used to establish singleton pregnancies in peripubertal adolescent sheep. This removes the confounding influence of variation in fetal number and by using a single sire and a small number of adult donors maximizes the homeogeneity of the resulting fetuses. The adolescent recipients are of equivalent age, liveweight and body condition score at the time of embryo transfer and, in addition, care is taken to randomize for ovulation rate and embryo source. The adolescent recipient dams are housed in individual pens throughout pregnancy to facilitate precise nutritional management. Immediately after embryo transfer on day 4 of the oestrous cycle, the recipient dams are offered either a high or moderate quantity of a complete diet to promote rapid or normal maternal growth, respectively. Typically, these two dietary manipulations result in a liveweight gain of $200-300 \mathrm{~g}$ per day compared with $50-75 \mathrm{~g}$ per day during the first 100 days of gestation and significant differences in liveweight and body condition score are easily detectable by the end of the first third of pregnancy. After day 100 of gestation the feed intake of the normally growing group is adjusted each week to maintain body condition score and to meet the increasing nutrient demand of the gravid uterus.

\section{Adolescent Pregnancy Outcome}

The key features of pregnancy outcome for adolescent dams offered a high or moderate nutrient intake throughout their entire pregnancy and delivering live young at term are summarized in Table 1. Overnourishing dams to promote rapid maternal growth throughout pregnancy results in a major restriction in total placental mass $(36 \%)$ and leads to a significant decrease in birthweight $(33 \%)$ relative to normally growing adolescents (Wallace et al., 1996, 1997b,c and J. M. Wallace, D. A. Bourke and R. P. Aitken, unpublished data). This somewhat paradoxical effect of overfeeding is consistent and completely repeatable between studies. Total placental mass and lamb birthweight are highly correlated in these adolescent animals (Fig. 1) but the placental fetal weight ratio is not altered significantly by nutritional treatment. For those ewes delivering live young, high nutrient intakes are associated with a shorter duration of gestation and, irrespective of treatment group, duration of gestation is positively correlated with both placental weight $(r=0.461, P<0.001)$ and lamb birthweight $(r=0.572, P<0.001)$. Maternal liveweight gains during the first 95 days of gestation were $281 \pm 8.1$ and $72 \pm 2.9 \mathrm{~g}$ per day for the high compared with the moderate intake 
Table 1. Duration of gestation, lamb birthweight, placental parameters and colostrum production in normally growing (moderate nutrient intake) versus rapidly growing (high nutrient intake) adolescent dams delivering live young.

\begin{tabular}{|c|c|c|c|}
\hline $\begin{array}{l}\text { Norr } \\
\text { Mod }\end{array}$ & $\begin{array}{l}\text { nal maternal growth } \\
\text { erate nutrient intake }\end{array}$ & $\begin{array}{l}\text { Rapid maternal growth } \\
\text { High nutrient intake }\end{array}$ & Significance \\
\hline Number of adolescents & 34 & 37 & \\
\hline $\begin{array}{l}\text { Duration of gestation (days) } \\
\text { (range) }\end{array}$ & $\begin{array}{l}145,1 \pm 0,50 \\
(142-158)\end{array}$ & $\begin{array}{l}142.4 \pm 0.42 \\
(135-147)\end{array}$ & $* *$ \\
\hline $\begin{array}{l}\text { Lamb birthweight (g) } \\
\text { (range) }\end{array}$ & $\begin{array}{c}4758 \pm 154 \\
(2950-7050)\end{array}$ & $\begin{array}{c}3175 \pm 123 \\
(1910-4560)\end{array}$ & *** \\
\hline $\begin{array}{l}\text { Total placental weight (g) } \\
\text { (range) }\end{array}$ & $\begin{array}{r}470 \pm 18.6 \\
(245-759)\end{array}$ & $\begin{array}{l}299 \pm 14.2 \\
(134-553)\end{array}$ & $* * *$ \\
\hline $\begin{array}{l}\text { Number of fetal cotyledons } \\
\text { (range) }\end{array}$ & $\begin{array}{r}97 \pm 2.9 \\
(54-127)\end{array}$ & $\begin{array}{r}78 \pm 2.6 \\
(44-107)\end{array}$ & $* * *$ \\
\hline $\begin{array}{l}\text { Total fetal cotyledon weight (g) } \\
\text { (range) }\end{array}$ & $\begin{array}{r}130 \pm 6.3 \\
(61-223)\end{array}$ & $\begin{array}{l}64 \pm 2.9 \\
23-98)\end{array}$ & $* * *$ \\
\hline $\begin{array}{l}\text { Mean fetal cotyledon weight } \\
\text { per placenta (g) } \\
\text { (range) }\end{array}$ & $\begin{array}{r}1.4 \pm 0.06 \\
(0.63-2.04)\end{array}$ & $\begin{array}{r}0.8 \pm 0.04 \\
(0.28-1.45)\end{array}$ & $* * *$ \\
\hline Fetal : placental weight ratio & $10.3 \pm 0.27$ & $11.2 \pm 0.38$ & n.s. \\
\hline Colostrum yield at parturition $(\mathrm{g}$ ) & $375 \pm 35.1$ & $128 \pm 19.5$ & $* * *$ \\
\hline
\end{tabular}

Values are means \pm SEM. Data summarized from Wallace et $a$ L, 1996, 1997a, b and J. M. Wallace, D. A. Bourke and R.P. Aitken, unpublished observations.

$* * * P<0.001$.

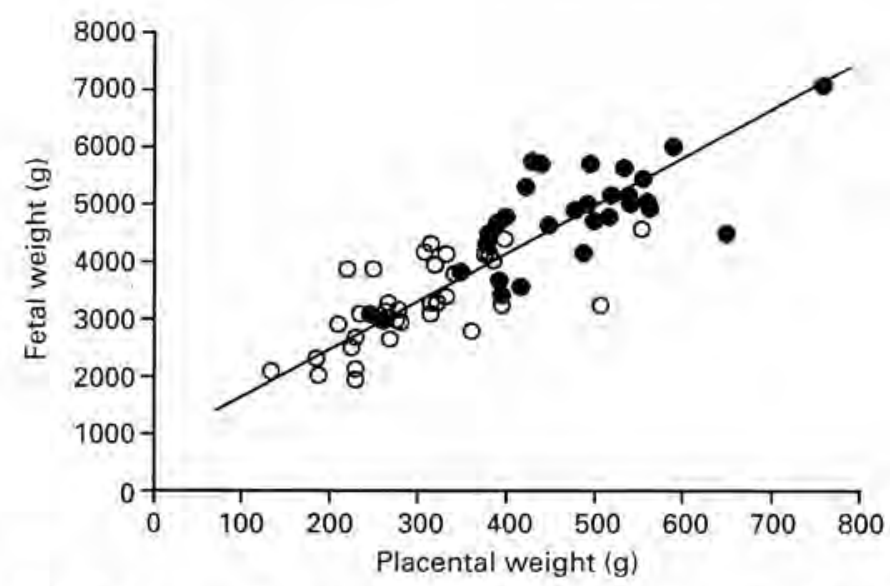

Fig. 1. Relationship between total placental weight and lamb birthweight in adolescent dams delivering singleton fetuses and offered a high $(0)$ or moderate $(\bullet)$ nutrient intake throughout pregnancy to promote rapid or normal maternal growth, respectively.

dams, respectively. Irrespective of treatment group, placental weight $(r=-0.593, P<0.001)$ and lamb birthweight $(r=-0.609, P<0.001)$ were correlated negatively with liveweight gain. As the adolescent dams are all the same age, these results strongly suggest that maternal nutritional status rather than gynaecological immaturity predisposes the adolescent to poor pregnancy outcome. 
Table 2. Relative differences in maternal concentrations of metabolic and placental hormones in adolescent dams offered a high or moderate nutrient intake throughout pregnancy. Arrows indicate when hormone concentrations (measured in blood samples collected one or three times a week) in high intake dams relative to moderate intake dams began to diverge significantly, and, where appropriate, the stage and direction of changes during gestation

\begin{tabular}{|c|c|c|c|}
\hline & \multicolumn{3}{|c|}{ Stage of gestation } \\
\hline & Early & Mid- & Late \\
\hline \multicolumn{4}{|l|}{ Metabolic hormones } \\
\hline Insulin & $\uparrow$ & $\uparrow$ & $\uparrow$ \\
\hline IGF-I & $\not$ & $\uparrow$ & $\dagger$ \\
\hline Tri-iodothyronine & $\rightarrow$ & $\pi$ & $\uparrow$ \\
\hline Thyroxine & $\rightarrow$ & $\rightarrow$ & $\uparrow$ \\
\hline $\mathrm{GH}^{*}$ & - & $\downarrow$ & $\downarrow$ \\
\hline \multicolumn{4}{|l|}{ Placental hormones } \\
\hline Progesterone & $\downarrow$ & $\downarrow$ & $\downarrow$ \\
\hline Pregnancy-specific protein B & $\downarrow$ & $\downarrow$ & $\downarrow$ \\
\hline
\end{tabular}

\section{Putative Endocrine Nutrient Partitioning Agents}

Maternal hormones such as insulin, insulin-like growth factor I (IGF-I), growth hormone and thyroid hormones do not cross the placenta in physiologically significant quantities (Brown and Thorburn, 1989), but may indirectly regulate nutrient partitioning between the maternal and fetal compartments via secondary changes in maternal or placental metabolism, utero-placental blood flow or placental growth and nutrient transport functions. Similarly, placental hormones such as progesterone, oestrogen and placental lactogen are secreted largely into the maternal circulation and are considered to modify maternal physiology to the advantage of the growing conceptus. Many of these putative endocrine regulators of gestational nutrient partitioning are highly nutritionally sensitive and, in contrast to the numerous studies outlined above in which the dam and her fetus are both undernourished, the adolescent model involves overnutrition of the dam and placentally mediated restriction of nutrient supply to the fetus. We have examined the circulating maternal concentrations of a number of putative endocrine partitioning agents in relation to placental and fetal growth in this paradoxical model (Wallace et al., 1997a,b) and the results are summarized in Table 2. High nutrient intakes are associated with high maternal insulin and, to a lesser extent, IGF-I concentrations from an early stage of gestation. These nutritionally sensitive hormones may ensure that the anabolic drive required to promote maternal tissue synthesis is initiated during the first third of pregnancy, at a time when the nutrient requirements for both placental and fetal growth are low. The potential for continuing maternal growth during pregnancy is high in the overnourished adolescent sheep and the major drive to maternal tissue deposition, particularly of adipose tissue, is maintained throughout gestation in spite of the gradually increasing nutrient demands of the gravid uterus. During normal pregnancy in the adult sheep, the amount of glucose available to non-uterine maternal tissues is reduced as pregnancy advances (Oddy et al,, 1985). It has been suggested that insulin and placental lactogen play key roles in mediating these metabolic changes. In adult ewes maternal insulin concentrations normally decrease during the final third of pregnancy and are inversely related to concentrations of placental lactogen (Vernon et al., 1981). It appears that placental lactogen may have a causative role because removal of the hormone during a 
short-term infusion with a specific antibody leads to a significant rise in maternal insulin concentrations (Waters et al., 1985). In contrast, in the overnourished adolescent, insulin concentrations continue to rise during the final third of pregnancy and may reflect low secretion of placental lactogen by the growth-restricted placenta. This, in turn, appears to result in increased glucose utilisation by the maternal tissues and continued lipid accumulation. Although we have not yet measured placental lactogen in these animals, we have clearly demonstrated that maternal peripheral concentrations of progesterone and of the pregnancy-specific protein B produced by the binucleate cells of the placenta were low throughout gestation in the overnourished animals and were associated positively with placental mass, particularly during the second half of gestation (Wallace et al., 1997a).

\section{Placental Growth}

The unexpected but major restriction in fetal growth, observed in rapidly growing mothers, occurs irrespective of high levels of essential nutrients available in the maternal circulation. High intake dams are relatively hyperglycaemic throughout gestation, and an attenuated glucose response to an exogenous insulin challenge during mid-and late pregnancy implies a degree of insulin resistance (Wallace et al., 1997b). Small size, altered metabolic and transport capacity of the placenta, or both factors may be the primary constraint to fetal growth in overnourished adolescent sheep.

The sheep has an epitheliochorialcotyledonary placenta and number and size of the individual cotyledons determine the available area for nutrient exchange between the maternal and fetal systems. The decrease in placental weight observed at term in the overnourished animals reflects a significant reduction in both the number of fetal cotyledons per placenta and mean fetal cotyledon weight (Table 1). These studies are the first to demonstrate consistently that maternal nutrition can influence the number of maternal caruncles used by the developing trophoblast. We are beginning to examine the putative nutritionally mediated endocrine mechanisms underlying this early pregnancy placental phenomenon.

Exogenous progesterone administration during the first 3 days of pregnancy enhanced fetal growth at day 74 of gestation by $11 \%$ (Kleemann et al., 1994). Although placental data were not reported, these researchers observed that progesterone influenced blastocyst differentiation in favour of the trophectoderm cells and stimulated earlier trophoblast elongation compared with control animals (Hartwich et al., 1995). Since maternal dietary intakes are related inversely to concentrations of progesterone in peripheral plasma in the adolescent dams (Table 2), it seemed probable that suboptimal progesterone in overnourished dams could compromise growth of the differentiating conceptus, resulting in fewer uterine caruncles being occupied. In a preliminary study of progesterone supplementation, we have investigated this hypothesis and the results are presented in Table 3. Progesterone concentrations were lower in high intake versus moderate intake dams. Daily administration of physiological doses of progesterone to a third group of high intake dams from day 5 to day 55 of gestation restored moderate circulating progesterone concentrations throughout the first third of pregnancy. Thereafter, peripheral progesterone concentrations were similar in the high intake and high intake plus progesterone groups and significantly lower than in the moderate intake group. At term, mean fetal weight in the high intake plus progesterone group was intermediate between the high and moderate intake groups but this increase in birthweight was not mediated by significant alterations in any of the gross placental measurements. These preliminary results on a very small number of animals do not preclude the possibility of more subtle effects of exogenous progesterone on placental morphology or nutrient exchange capacity, but progesterone may be influencing the inner cell mass directly.

The IGF system may play a pivotal role in the regulation of early placental growth in that the ovine placenta contains type 1 receptors for IGFs throughout gestation (Lacroix et al., 1995; Reynolds et al., 1997a). These receptors could be a target for locally produced or circulating IGFs from the maternal or fetal circulation and hence may have a role in the proliferative growth or metabolic 
Table 3. Influence of progesterone supplementation in high intake ewes during the first third of pregnancy on peripheral progesterone concentrations and pregnancy outcome

\begin{tabular}{lccc}
\hline & \multicolumn{3}{c}{ Maternal nutrient intakes } \\
& Moderate & High & $\begin{array}{c}\text { High + progesterone } \\
\text { (Day 5-55 of gestation) }\end{array}$ \\
\hline $\begin{array}{l}\text { Number of adolescents } \\
\text { *Progesterone concentrations }\end{array}$ & 7 & 6 & 7 \\
(ng ml-1) first trimester & $8.7 \pm 0.68$ & $6.6 \pm 0.91$ & $9.5 \pm 1.05$ \\
$\quad$ second trimester & $11.8 \pm 0.78$ & $6.5 \pm 1.46$ & $6.3 \pm 0.63$ \\
$\quad$ third trimester & $20.9 \pm 1.60$ & $7.1 \pm 1.17$ & $8.6 \pm 1.10$ \\
Lamb birthweight (g) & $5164 \pm 150$ & $3118 \pm 363$ & $4150 \pm 389$ \\
Total placental weight (g) & $498 \pm 18.9$ & $313 \pm 65.9$ & $318 \pm 41.5$ \\
Fetal cotyledon number & $85 \pm 6.9$ & $83 \pm 10.4$ & $76 \pm 12.6$ \\
Total fetal cotyledon weight (g) & $136 \pm 12.1$ & $61 \pm 8.9$ & $76 \pm 10.2$ \\
\hline
\end{tabular}

Values are means $\pm 5 E M$. J. M. Wallace, D. A. Bourke and R. P. Aitken, unpublished.

*Based on overall mean individual progesterone concentrations measured in blood samples collected three times a week.

activity of the developing placenta. In the overnourished adolescent, maternal IGF-I concentrations are high while placental growth is restricted. Preliminary data indicate that utero-placental IGF-I receptor expression at the end of the second third of pregnancy is low in these animals (Reynolds et al., 1997b). Prolonged exposure to high maternal IGF-I concentrations may downregulate placental IGF-I receptor expression and hence placental growth. Alternatively, if placentally derived IGF-I plays a major autocrine role in placental growth, attenuated IGF-I secretion by the growth-restricted placenta per se may be a secondary consequence of reduced nutrient availability at the utero-placental level.

We intend to extend these studies on the nutritionally mediated mechanisms underlying early placental growth to investigate the role of maternal nutrition on the utero-placental secretion and expression of the angiogenic growth factors and how these relate to blood vessel formation and utero-placental blood flow.

\section{Nutritionally Sensitive Windows of Placental Growth and their Reversibility}

Although the number of cotyledonary attachment sites occupied by the developing trophoblast is fixed by day 30 of gestation (Barcroft and Kennedy, 1939), the proliferative growth of the placenta continues until the end of the second third of pregnancy. A recent study has examined whether placental growth and hence pregnancy outcome can be altered by switching adolescent dams from an anabolic to a catabolic state, and vice versa, at the end of the first third of pregnancy (Wallace et al., 1997c). After embryo transfer adolescent dams were offered a high $(H, n=33)$ or moderate $(\mathrm{M}, n=32)$ nutrient intake to promote rapid or normal maternal growth as described previously. At day 50 of gestation half the ewes had their dietary intakes switched to yield $\mathrm{HH}, \mathrm{MM}, \mathrm{HM}$ and $\mathrm{MH}$ treatments (Fig. 2). After day 100, feed intake of the MM and HM group was adjusted weekly to maintain body condition score during the final trimester. A subset of ewes ( $n=4$ or 5 per group) were slaughtered at day 104 of gestation, while the remaining ewes were allowed to deliver spontaneously. For ewes maintaining pregnancies to term, total placental mass $(258 \pm 33$ versus $457 \pm 75 \mathrm{~g})$, fetal cotyledon number $(79 \pm 7.8$ versus $103 \pm 3.4)$, mean cotyledon weight $(0.7 \pm 0.06$ versus $1.3 \pm 0.19 \mathrm{~g})$ and lamb birthweight $(3.03 \pm 0.34$ versus $4.94 \pm 0.57 \mathrm{~kg})$ were lower $(P<0.02)$ in $\mathrm{HH}$ than in $\mathrm{MM}$ groups as reported above for earlier studies. Abruptly decreasing maternal dietary intake at the end of the first third of the pregnancy $(\mathrm{HM})$ resulted in a moderate but non-significant increase 

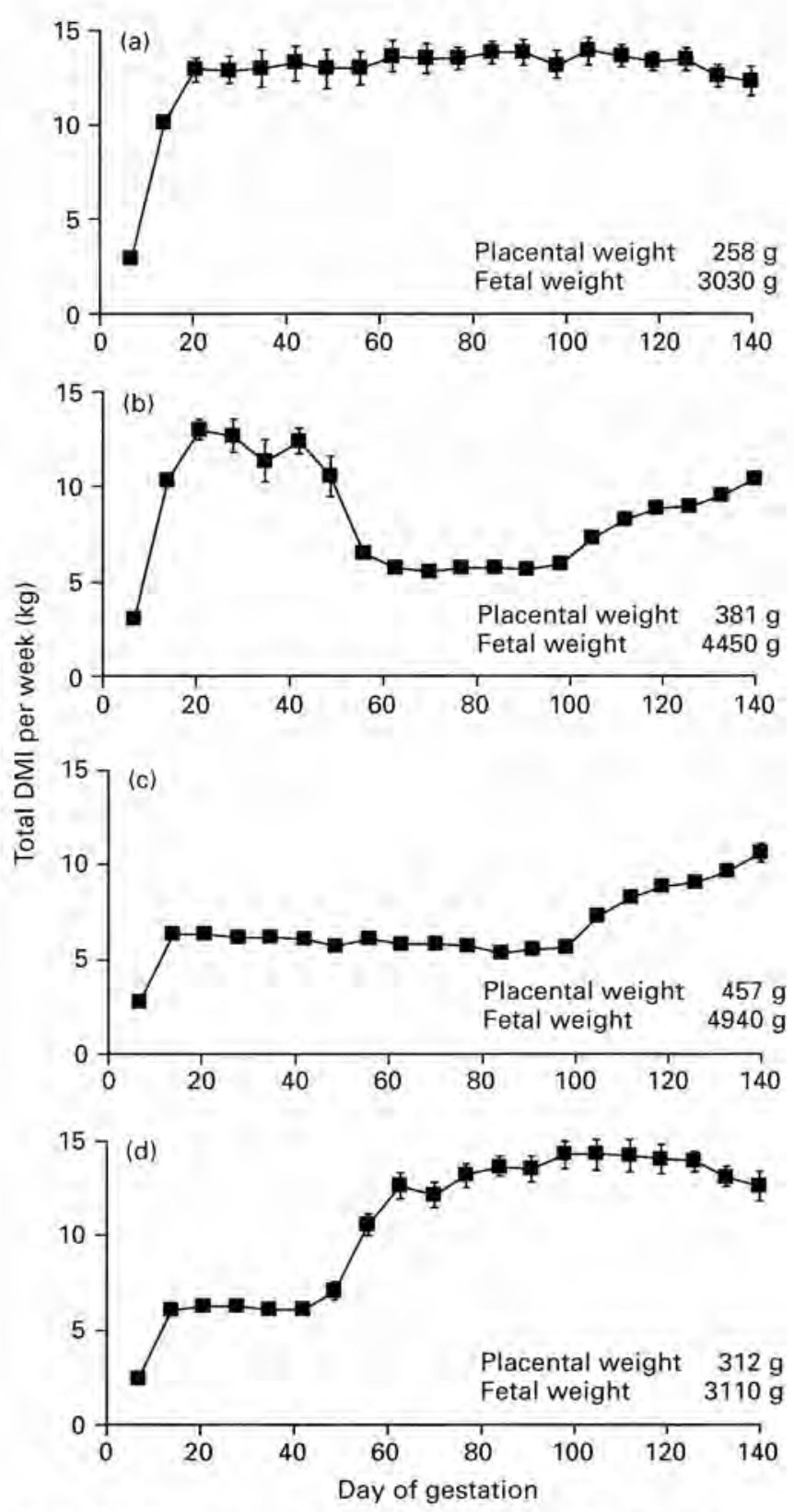

Fig. 2. Weekly dry matter intakes (DMI) throughout gestation in relation to pregnancy outcome in adolescent dams delivering singleton fetuses. After embryo transfer ewes were initially offered a high $(\mathrm{H})$ or moderate $(\mathrm{M})$ nutrient intake to promote rapid or normal maternal growth. At day 50 of gestation half the ewes in each treatment had their dietary intakes switched to yield (a) $\mathrm{HH}$ $(n=7)$, (b) HM ( $n=9)$, (c) MM $(n=6)$ and (d) MH $(n=8)$ treatments. After day 100 , feed intake of the MM and HM groups was adjusted weekly to maintain body condition score during the final third of pregnancy. 
(a)

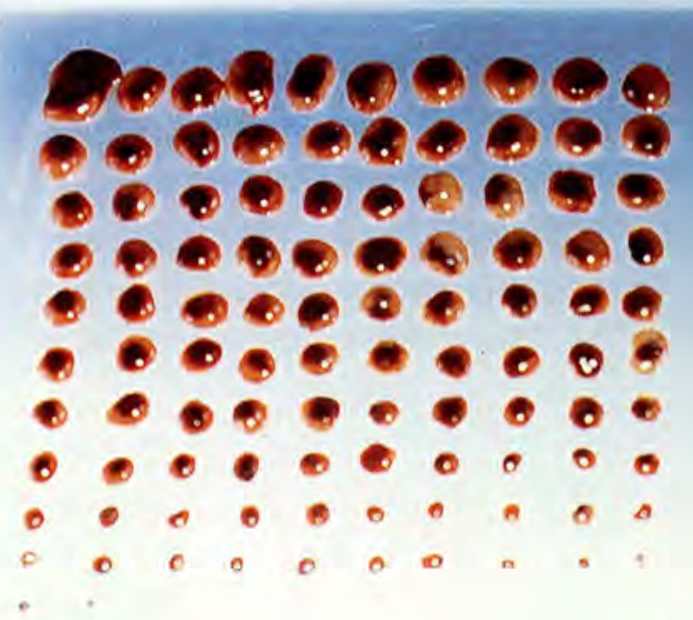

(b)

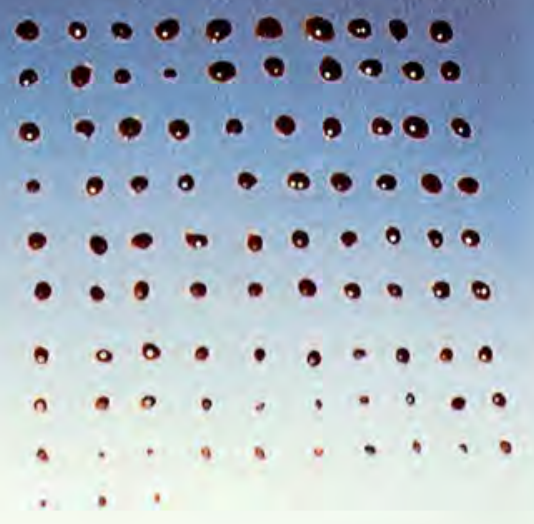

Fig. 3. Individual fetal cotyledons dissected on day 104 of gestation from (a) an adolescent ewe offered a moderate intake for the first two thirds of gestation and (b) an adolescent ewe offered a moderate intake for the first third followed by a high intake for the second third of gestation.

in the number of fetal cotyledons (18\%) and a major stimulation in individual cotyledon weight $(1.1 \pm 0.13 \mathrm{~g}, P<0.05)$ compared with the $\mathrm{HH}$ group. Consequently, lamb birthweights in the HM group $(4.45 \pm 0.34 \mathrm{~kg})$ were equivalent to the MM group. In contrast, ewes initially on moderate intakes had a normal number of cotyledons $(109 \pm 3.9)$ and when their intakes were increased markedly at the end of the first third of pregnancy $(\mathrm{MH})$, the growth of the individual cotyledons was severely reduced $(0.6 \pm 0.07 \mathrm{~g}, P<0.01)$ relative to the MM group (Fig. 3). Hence total placental mass was lower $(312 \pm 22 \mathrm{~g})$ and lead to a major restriction in fetal growth $(3.11 \pm 0.24 \mathrm{~kg}, P<0.02)$. Dissection of the placenta at day 104 of gestation revealed that moderate nutrient intakes during mid-gestation preferentially stimulate growth of the fetal rather than the maternal component of the placenta; total fetal cotyledon weight in $\mathrm{MM}$ and $\mathrm{HM}$ compared with $\mathrm{HH}$ and $\mathrm{MH}$ groups was $196 \pm 18.1$ versus $104 \pm 19.8 \mathrm{~g}$, $P<0.02$, while maternal cotyledon weight was $157 \pm 20.5$ versus $120 \pm 19.8 \mathrm{~g}$, respectively. At this stage of gestation, the fetus weighs less than a third of its potential birthweight and mean fetal weights in the various nutritional treatment groups were not significantly different. However, a positive relationship between placental size and fetal growth was already evident since, irrespective of treatment group, fetal weight $(r=0.650)$ and the weight of the fetal liver $(r=0.760)$, spleen $(r=0.784)$, kidneys $(r=0.521)$ and intestines $(r=0.599)$ were significantly correlated with total cotyledon mass. Thus, in this highly controlled nutritionally sensitive paradigm, reducing maternal dietary intake at the end of the first third of the pregnancy can stimulate placental growth and enhance pregnancy outcome, but increasing dietary intake at this time has a deleterious effect on placental development and fetal growth. These nutritional switch-over studies have obvious implications for both agricultural and clinical practice. In humans, intrauterine growth restriction is rarely diagnosed before the final third of the pregnancy and is associated primarily with poor placental growth. It remains to be established in this overnourished sheep model whether abruptly reducing maternal nutrient intake at the end of the second third of pregnancy can alter the metabolic and transport functions of a stunted placenta to redirect essential nutrients to the fetus. 
Table 4. Conformation and absolute fetal organ weights of singleton fetuses derived from dams that were offered a high or moderate nutrient intake from day 4 after oestrus until slaughter on day 128 of gestation:

\begin{tabular}{|c|c|c|c|}
\hline & $\begin{array}{l}\text { Normal Maternal Growth } \\
\text { Moderate Nutrient Intake }\end{array}$ & $\begin{array}{l}\text { Rapid Maternal Growth } \\
\text { High Nutrient Intake }\end{array}$ & Significance \\
\hline Number of dams/fetuses & 7 & 7 & \\
\hline Total cotyledon weight ${ }^{\mathrm{a}}(\mathrm{g})$ & $448 \pm 23.5$ & $219 \pm 34.7$ & *** \\
\hline Fetal weight (g) & $4190 \pm 87$ & $2645 \pm 385$ & ** \\
\hline Biparietal head diameter $(\mathrm{mm})$ & $67.9 \pm 0.46$ & $58.9 \pm 2.57$ & ** \\
\hline Umbilical girth $(\mathrm{cm})$ & $34.8 \pm 0.63$ & $27.0 \pm 1.81$ & ** \\
\hline Crown-rump length (cm) & $49.4 \pm 0.70$ & $41.5 \pm 2.72$ & * \\
\hline Brain (g) & $40.8 \pm 1.24$ & $34.5 \pm 1.61$ & ** \\
\hline Lungs (g) & $156.8 \pm 7.54$ & $95.8 \pm 15.8$ & $* *$ \\
\hline Heart $(\mathrm{g})$ & $33.2 \pm 1.01$ & $22,7 \pm 3.57$ & * \\
\hline Liver $(\mathrm{g})$ & $128.7 \pm 3.86$ & $75.0 \pm 11.8$ & $* * *$ \\
\hline Kidneys (g) & $28.1 \pm 0.81$ & $19.5 \pm 2.28$ & ** \\
\hline Empty gut (g) & $136.6 \pm 4.62$ & $94.7 \pm 14.38$ & $*$ \\
\hline Pancreas (g) & $4.03 \pm 0.148$ & $2.39 \pm 0.344$ & *** \\
\hline Spleen $(g)$ & $7.35 \pm 0.338$ & $4.82 \pm 1.017$ & $*$ \\
\hline Adrenals (g) & $0.49 \pm 0.023$ & $0.41 \pm 0.034$ & ns \\
\hline Thyroid (g) & $0.89 \pm 0.067$ & $0.58 \pm 0.104$ & * \\
\hline Gastrocnemius muscle (g) & $8.11 \pm 0.344$ & $5.45 \pm 0.816$ & * \\
\hline Empty carcass (g) & $2655 \pm 61.8$ & $1624 \pm 254.6$ & $* *$ \\
\hline
\end{tabular}

Values are means \pm SEM. J. M. Wallace, D. A. Bourke and R. P. Aitken, unpublished data.

- Combined fetal cotyledon and maternal caruncle weight.

*** $P<0.001, * P<0.01,{ }^{*} P<0.05 ;$ ns, not significant.

\section{Consequences of a Disrupted Growth Trajectory}

We are examining the consequences of a disrupted placental growth trajectory on fetal organ growth, structure and function. An initial study compared fetuses at day 128 of gestation from adolescent dams that were overnourished or moderately fed throughout pregnancy and had growth restricted and normal placentae, respectively (Table 4). All variables of fetal conformation and absolute fetal organ weights, with the exception of the adrenals, were significantly lower in the fetuses from overnourished dams. However, relative organ and tissue weights expressed as g per $\mathrm{kg}$ fetal body or fetal empty carcass weight were not influenced significantly by maternal nutrient intake (data not shown), with the exception of the gut. The implication is that growth restriction in these fetuses is largely symmetrical as indicated by the allometric plots for three of the major fetal organs (Fig. 4). Analysis of single blood samples collected immediately before these fetuses were killed reveals that concentrations of insulin, IGF-I and glucose were significantly attenuated in growth-restricted fetuses from overnourished dams. In addition, plasma urea was high, indicating that the fetuses may be relatively catabolic compared with the normally growing fetuses from the moderately fed dams. Detailed examination of the effects of maternal nutrition on the functional development of the major fetal organ systems in late gestation fetuses has been initiated. Of key economic interest to all agricultural sectors is the concept that aspects of our adult reproductive potential may be programmed during prenatal life. Thus, it is potentially significant that we have detected reduced expression of LH and FSH- $\beta$ mRNAs in the fetal pituitary of severely growth restricted versus normally growing late gestation fetuses. Moreover, we have observed alterations in gonadal germ cell number and stage of differentiation at this developmental time, which may be GnRH dependent, and which could underlie reduced postnatal reproductive capability (P. Da. Silva, N. Brooks, S. M. Rhind and J. M. Wallace, unpublished data). 

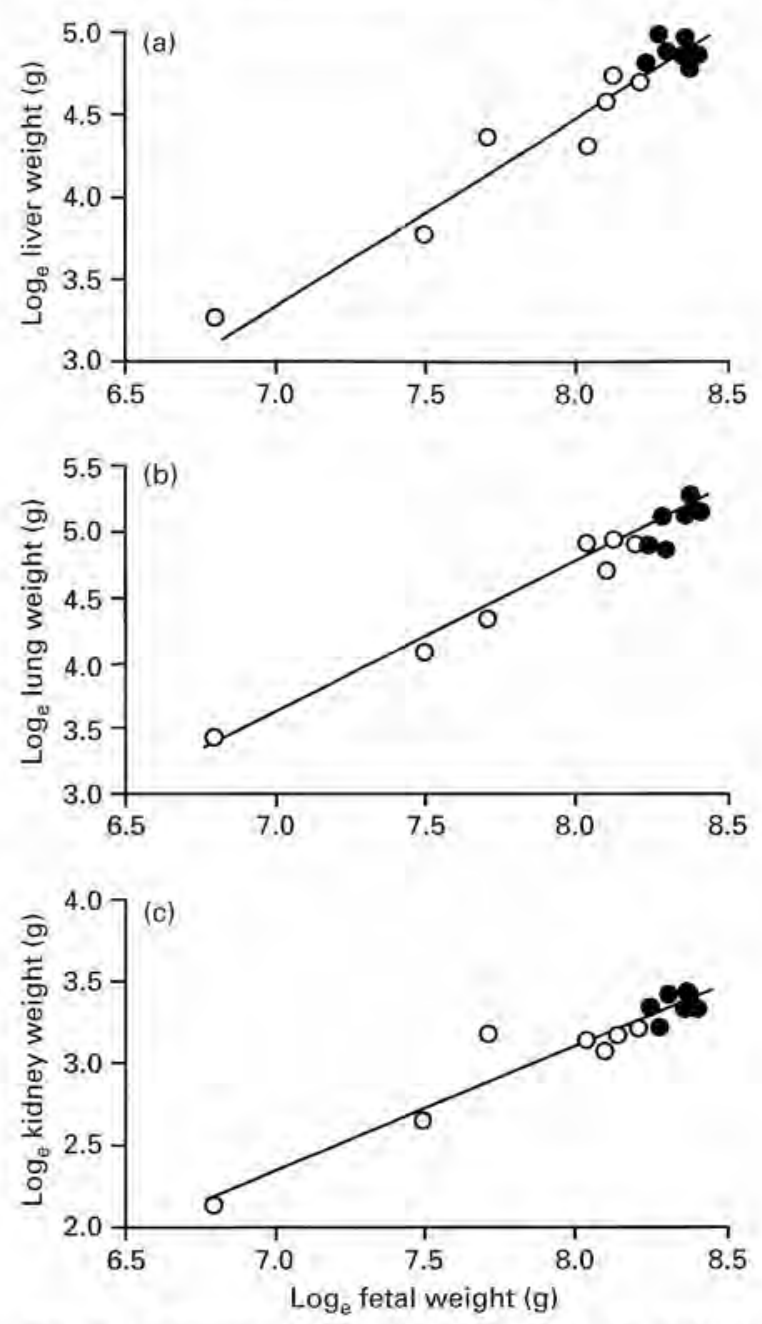

Fig. 4. Allometric plots of (a) liver, (b) lungs and (c) kidneys of fetuses from dams offered a high (O) or moderate $(\bullet)$ nutrient intake throughout pregnancy and killed on day 128.

\section{Conclusion}

We have demonstrated that inadequate placental growth is the primary limitation to fetal growth in the overnourished adolescent sheep. Consequently, the growing adolescent sheep provides a new and non-invasive paradigm to investigate the putative nutritionally mediated endocrine and paracrine mechanisms underlying early placental growth. The restriction in fetal growth in overnourished dams occurs in spite of the ready availability of nutrients in the maternal system and future studies will determine placental uptake, metabolism and transfer of nutrients by the growthrestricted placenta to the developing fetus. Initial studies indicate that this form of placentally mediated fetal growth restriction programmes a legacy of structural and functional defects that may have a major impact on postnatal health, growth and development. As such, this paradoxical adolescent sheep model is of major agricultural and clinical relevance and may play a key role in the 
development of more informed nutritional strategies to alleviate or prevent intrauterine growth retardation.

The authors thank P. Da Silva and M. Cruickshank for technical assistance and gratefully acknowledge the continued financial support of the Scottish Office Agriculture Environment and Fisheries Department.

\section{References}

Alexander G (1974) Birth weight of lambs: influences and consequences. In Size at Birth pp 215-239. Eds K Elliot and J Knight. Associated Scientific Publishers, Amsterdam

Barcroft J and Kennedy JA (1939) The distribution of blood flow between the fetus and placenta in sheep Journal of Physiology 95 173-186

Bell AW (1984) Factors controlling placental and foetal growth and their effects on future production. In Reproduction in Sheep pP 144-152. Eds DR Lindsay and PT Pearce. Australian Academy of Science, Canberra

Bell AW (1992) Foetal growth and its influence on postnatal growth and development. In The Control of Fat and Lean Deposition pp 111-127. Eds KN Boormann, PJ Buttery and DB Lindsay. Butterworth-Heinemann Ltd, Oxford

Brown CA and Thorbum GD (1989) Endocrine control of fetal growth Biology of the Neonate 55 331-346

Cumming IA, Blockey MADeB, Winfield CG, Parr RA and Williams AH (1975) A study of the relationships of breed, time of mating, level of nutrition, live weight, body condition, and face cover to embryo survival in ewes Journal of Agriculitural Science 84 559-565

De Barro TM, Owens JA, Earl CR and Robinson JS (1992) Nutrition during early pregnancy interacts with mating weight to affect placental growth Proceedings of the Australian Society of Reproductive Biology 3570 (Abstract)

Edey TN (1966) Nutritional stress and pre-implantation embryonic mortality in Merino sheep Joumal of Agricultural Science 67 287-293

Ehrhardt RA and Bell AW (1995) Growth and metabolism of the ovine placenta during mid-gestation Placenta 16 727-741

Farin PW, Farin CE and Yang L (1994) In vitro production of bovine embryos is associated with altered fetal development Theriogenology 41193 (Abstract)

Fleming JV, Hay SM, Harries N and Rees WD (1998) Effects of nutrient deprivation and differentiation on the expression of growth-arrest genes (gas and gadd) in F9 embryonal carcinoma cells Biochemical Journal $330573-579$

Fraser AM, Brockert JE and Ward RH (1995) Association of young maternal age with adverse reproductive outcomes The New England Journal of Medicine 332 1113-1117

Gardner DK, Lane M, Spitzer A and Batt PA (1994) Enhanced rates of cleavage and development for sheep zygotes cultured to the blastocyst stage in vitro in the absence of serum and somatic cells: amino acids, vitamins and culturing embryos in groups stimulate development Biology of Reproduction 50 390-400

Gunn RG, Sim DA and Hunter EA (1995) Effects of nutrition in utero and in early life on the subsequent lifetime reproductive performance of Scottish Blackface ewes in two management systems Animal Science 60 223-230

Hammond J (1944) Physiological factors affecting birthweight Proceedings of The Nutrition Society 2 8-14

Harding JE and Johnston BM (1995) Nutrition and fetal growth Reproduction Eertility and Development 7 539-547
Hartwich KM, Walker SK, Owens JA and Seamark RF (1995) Progesterone supplementation in the ewe alters cell allocation to the inner cell mass Proceedings of the Austratian Society of Medical Research 26128 (Abstract)

Heasman L, Clarke L, Firth K, Stephenson T and Symonds ME (1998) Influence of restricted maternal nutrition in early to mid gestation on placental and fetal development at term. in sheep Paediatric Rescarch (in press)

Hinch GN, Lynch JJ, Nolan JV, Leng RA, Bindon BM and Piper LR (1996) Supplementation of high fecundity Border Leicester $\times$ Merino ewes with a high protein feed: its effect on lamb survival Australian Journal of Experimental Agriculture 36 129-136

Kelly RW (1992) Nutrition and placental development Proceedings of The Nutrition Society of Australia 17 203-211

Kelly RW, Macleod I, Hynd P and Greeff J (1996) Nutrition during fetal life alters annual wool production and quality in young Merino sheep Australian Journal of Experimental Agriculture 36 259-267

Kleemann DO, Walker SK and Seamark RF (1994) Enhanced fetal growth in sheep administered progesterone during the first three days of pregnancy Journal of Reproduction and Fertility $102411-417$

Lacroix MC, Servely JL and Kann G. (1995) IGE-I and IGF-II receptors in the sheep placenta: evolution during the course of pregnancy Journal of Endocrinology 144 179-191

McAnarney ER (1987) Young maternal age and adverse neonatal outcome American Journal of Disenses of Children 141 1053-1059

McEvoy TG, Robinson JJ, Aitken RP, Findlay PA, Palmer RM and Robertson IS (1995) Dietary-induced suppression of preovulatory progesterone concentrations in superovulated ewes impairs the subsequent in vivo and in vitro development of their ova Animal Reproduction Science 39 89-107

McEvoy TG, Robinson JJ, Aitken RP, Findlay PA and Robertson IS (1997) Dietary excesses of urea influence the viability and metabolism of preimplantation sheep embryos and may affect fetal growth among survivors Animal Reproduction Science $4771-90$

Maxfield EK, Sinclair KD, Dolman DE, Staines ME and Maltin CA (1997) In vitro culture of sheep embryos increases weight, primary fibre size and secondary to primary fibre ratio in fetal muscle at day 61 of gestation Theriogenology 47376 (Abstract)

Mellor DJ (1983) Nutritional and placental determinants of foetal growth rate in sheep and consequences for the newborn lamb British Veterinary Journal 139 307-324

Mellor DJ and Matheson IC (1979) Daily changes in the curved crown-rump length of individual sheep fetuses during the last 60 days of pregnancy and effects of different levels of maternal nutrition Quarterly Journal of Experiments! Plysiology 64 119-131

Mellor DJ and Murray L (1982) Effects on the rate of increase in 
fetal girth of refeeding ewes after short periods of severe undernutrition during late pregnancy Research in Veterinary Science 32 377-382

Oddy VH, Gooden JM, Hough GM, Teleni E and Annison EF (1985) Partitioning of nutrients in Merino ewes II Glucose utilisation by skeletal muscle, the pregnant uterus and the lactating mammary gland in relation to whole body glucose utilisation Australian Journal of Biological Science 38 $95-108$

Parr RA (1992) Nutrition-prógesterone interactions during early pregnancy in sheep Reproduction Fertility and Development 4 297-300

Parr RA, Williams AH, Cambell IP, Witcome GF and Roberts AM (1986) Low nutrition of ewes in early pregnancy and the residual effect on the offspring Journal of Agricultural Science 106 81-87

Parr RA, Davis IF, Fairclough RJ and Miles MA (1987) Overfeeding during early pregnancy reduces peripheral progesterone concentration and pregnancy rate in sheep Journal of Reproduction and Fertility $80317-320$

Reynolds TS, Stevenson KR and Wathes DC (1997a) Pregnancyspecific alterations in the expression of the insulin-like growth factor system during early placental development in the ewe Endocrinology 138 886-897

Reynolds TS, Wathes DC, Aitken RP and Wallace JM (1997b) Effect of maternal nutrition on components of the insulinlike growth factor (IGF) system and placental growth Journal of Endocrinology 152 (Supplement) p248

Rhind SM (1992) Nutrition: its effects on reproductive performance and its hormonal control in female sheep and goats. In Progress in Sheep and Goat Research pp 25-52 Ed. AW Speedy. CAB International, Oxford

Robinson JJ (1983) Nutrition of the pregnant ewe. In Sheep Production pp 111-131 Ed. W Haresign. Butterworths, London

Robinson JJ (1987) Energy and protein requirements of the ewe. In Recent Advmces in Animal Nutrition pp187-204 Eds W Haresign and DJA Cole. Butterworths, London

Robinson JJ (1990) Nutrition in the reproduction of farm animals Nutrition Research Revieus 3 253-276

Russel AJE, Foot JZ and White IR (1981) The effect of weight at mating and of nutrition during mid-pregnancy on the birthweight of lambs from primiparous ewes journal of Agricultural Science 97 723-729

Sinclair KD, Maxfield EK, Robinson JJ, Maltin CA, McEvoy TG, Dunne LD, Young LE and Broadbent PJ (1997) Culture of sheep zygotes can alter fetal growth and development Theriogenology 47380 (Abstract)

Thompson JG, Gardner DK, Pugh PA, McMillan WH and Tervit HR (1994) Lamb birthweight following transfer is affected by the culture system used for pre-elongation development of embryos Tournal of Reproduction and Fertility Abstract Series 13 Abstract 25

Vernon RG, Clegg RA and Flint DJ (1981) Metabolism of sheep adipose tissue during pregnancy and lactation Biochemistry foumal $200307-314$

Vincent IC, Williams HIL! and H!I! $\mathrm{R}$ (1985) The influence of a low-nutrient intake after mating on gestation and perinatal survival of lambs British Veterinary Journal 141 611-617

Walker SK, Heard TM and Seamark RF (1992) In vitro culture of sheep embryos without co-culture: successes and perspectives Theriogenology $37111-126$

Wallace JM, Aitken RP and Cheyne MA (1994) Effect of postovulation nutritional status in ewes on early conceptus survival and growth in vivo and luteotrophic protein secretion in vitro. Reproduction, Fertility and Development 6 253-259

Wallace JM, Aitken RP and Cheyne MA (1996) Nutrient partitioning and fetal growth in rapidly growing adolescent ewes Journal of Reproduction and Eerfility 107 183-190

Wallace JM, Aitken RP, Cheyne MA and Humblot P (1997a) Pregnancy-specific protein B and progesterone concentrations in relation to nutritional regimen, placental mass and pregnancy outcome in growing adolescent ewes carrying singleton fetuses Journal of Reproduction and Fertility 10953-58

Wallace JM, Da Silva P, Aitken RP and Cruickshank MA (1997b) Maternal endocrine status in relation to pregnancy outcome in rapidly growing adolescent sheep Journal of Endocrinology 155 359-368

Wallace JM, Bourke DA, Aitken RP and Cruickshank MA (1997c) Effect of switching maternal nutrient intake at the end of the first trimester on placental development and fetal growth in adolescent sheep carrying singleton fetuses Journal of Reproduction and Fertility Abstract Series 19 Abstract 21

Waters MJ, Oddy VH, McCloghry CE, Gluckmann PD, Duplock R, Owens PC and Brinsmead MW (1985) An examination of the proposed roles of placental lactogen in the ewe by means of antibody neutralization Journal of Endocrinology 106 377-386

Williams AH (1984) Long-term effects of nutrition of ewe lambs in the neonatal period. In Reproduction in Sheep pp 272-273. Eds DR Lindsay and PT Pearce. Australian Academy of Science, Canberra

Williams AH and Cumming IA (1982) Inverse relationship between concentration of progesterone and nutrition in ewes Journal of Agricultural Science 98 517-522 